\title{
Complementaritatea între teologie şi ştiinţă în cosmologie
}

Eugen GANŢOLEA*

Abstract: Science and theology are covering two distinct domains of our reality: physics and metaphysics, using two distinct methods of investigation: epistemology and gnoseology, respectively. As such, a conflict between science and theology should not possible because there is no overlapping area. Science only offers paradigmatic explanations of how the universe works, without having the scope to offer scientific explanations for the cause and purpose of the universe and all beings' existence. On the other hand, using gnoseology, Christian Orthodox theology, especially the apophatic one, is able to offer spiritual ontological understanding for the cause and scope of the universe and all beings'existence, without offering detailed functional explanations for them.

Keywords: Saint Luke of Crimea, Creation, Cosmology, Science, Theology.

* PhD Candidate, Faculty of Orthodox Theology at "Lucian Blaga" University
in Sibiu, Romania. 
Este o certitudine astăzi, că ,pentru un fizician, a admite modelul big bang-ului înseamnă să recunoască imposibilitatea extrapolării la nesfârșit înspre trecut cu ajutorul legilor fizicii. [...] $\mathrm{Nu}$ știm nimic despre originea universului, și nici despre originea timpului, fie ca termenul origine este luat aici in sens cronologic sau in sens explicativ."

Realitatea lumii în care trăim are mai multe nivele. Noi relaționăm cu ceea ce numim realitate fizică prin intermediul percepției senzoriale. $\mathrm{Cu}$ ajutorul rațiunii suntem capabili sa percepem nivelul metafizic al realității matematice. Prin intermediul intelectului, putem avea percepția extra senzoriala a nivelului spiritual. De asemenea, tot cu ajutorul intelectului avem cogniția frumosului, binelui etc. Demersul științific are ca scop oferirea unei explicații paradigmatice complete a modului în care funcționează universul. Știința nu își propune să explice scopul existențial al acestui mod de funcționare și nici cauza lui. Pe de altă parte, teologia oferă explicații doar cu privire la cauza și scopul existenței universului, fără a oferi informații tehnice cu privire la modul funcționare. Astfel, știința și teologie sunt complementare, neexistând suprapunere între ele.

Explicațiile funcționale ale universului, oferite de ştiinţă, trebuie interpretate pentru a li se conferi un sens existențial, gnoseologia teologica fiind chemată astfel să extindă cogniția umană în sfera metafizică prin cunoașterea duhovniceasca.

„Gnoseologia teologică nu constituie o simplă preocupare teoretică și o lucrare a dogmatiștilor, ci este însăși modul de viață al membrilor trupului Bisericii." ${ }^{2}$ Intre teologia ortodoxă

\footnotetext{
${ }^{1}$ Dominique Lecourt, Dicționar de istoria și filozofia științelor, trad. (coord.) Laurențiu Zoicas, București, Edit. Polirom, 2009. p.1397.

${ }^{2}$ Nikolaos Matsoukas, Introducere în gnoseologia teologică, trad. Maricel Popa, București, Edit. Bizantină, 1997. p. 17.
} 
hristocentrică $($ Col 1,16) și orice filozofie materialistă (scientismul spre exemplu) există opoziție evidenta, axata pe antropologie, cu implicaţiile ontologice directe.

Cosmologia Sfintei Scripturi în interpretarea patristică (alegorică în aceea ce privește exclusiv modul creaționist de funcționare al universului și nicidecum cauza și scopul existentei universului care este inechivoc hristocentric), evidențiind antropologia teologică ortodoxa (în opoziție cu antropologia filozofica materialista reducționist fiziologică), este prezentată pertinent, elocvent și succint în contemporaneitate de către Sfântul Luca Arhiepiscopul Crimeii: „s-a dovedit că în lumea celor mai mici particule cunoscute nouă - molecule, atomi, electroni etc. -, mecanica clasică își încetează aplicabilitatea și trebuie să cedeze locul unei teorii mult mai precise, dar care în același timp este mai complexă și mai abstractă: mecanica cuantică." ${ }^{3}$ Mecanica cuantică nu este ceva ce contrazice integral mecanica clasică, ci o include pe aceasta ca pe un domeniu înrudit, necesar în examinarea obiectelor cu masă moleculară suficient de mare.

Pe de altă parte, pentru procesele care se desfășoară cu viteze mari de deplasare, apropiate de cea a luminii, mecanica clasică încetează, de asemenea, să mai aibă aplicabilitate și este necesar să fie înlocuită cu mult mai riguroasa teorie a mecanicii relativiste, care se bazează pe teoria relativității a lui Einstein [Albert Einstein este autorul teoriei relativității, datorită căreia a primit premiul Nobel pentru fizică în anul 1921. A trăit între anii 1879-1955].

„Legile constanței elementelor nu mai există, deoarece este incontestabil dovedită transformarea unor elemente în altele. S-a constatat că există elemente cu aceeași masă atomică, dar cu proprietăți chimice diferite. [...] Atomul a încetat să mai constituie

${ }^{3}$ St Luca al Crimeii, Puterea inimii, trad. Savga Evdochia, București, Sophia, 2010, pp. 17-23. 
unitatea primordială a materiei, deoarece s-a constatat că structura lui este extrem de complexă. Particulele cele mai mici ale materiei cunoscute în prezent sunt electronii și pozitronii. Și unii, și alții au aceeași masă, dar se deosebesc prin sarcina electrică: electronul are sarcină electrică negativă, iar pozitronul pozitivă."4

In afara acestor particule, sunt și altele cu o greutate mai mare: protonii și neutronii, care alcătuiesc nucleul. Și masa lor este asemănătoare (de 1840 ori mai mare decât greutatea electronilor), dar în timp ce protonul este încărcat pozitiv, neutronul nu are sarcină electrică.

In ultima vreme, în componența razelor cosmice care ajung în atmosfera noastră din spațiul interstelar, a fost descoperită o serie întreagă de noi particule a căror greutate se cuprinde într-un interval destul de larg (de la 100 la 30.000 de mase electronice). Aceste particule poartă diverse denumiri: mezoni. De asemenea, s-a constatat că aceste particule nu sunt absolut constante. Protonii se pot transforma în neutroni și invers, electronii, unindu-se cu pozitronii, pot să înceteze să existe ca particule, transformânduse în radiație electromagnetică. Pe de altă parte, în condiții cunoscute, câmpul electromagnetic poate ,genera” câteva perechi de electroni-pozitroni. Particulele detectate în radiația cosmică pot să își modifice semnificativ masa în procesul de interferență cu atomii atmosferei.

În literatura actuală în materie de fizică, transformarea unei perechi electron-pozitron în radiație este numită „,anihilare” (distrugere) a materiei, procesul invers fiind numit ,materializare”.

„Noi nu avem dreptul și nici motivul de a sta împotriva realizărilor celor mai importante ale fizicii modeme. ${ }^{95} \mathrm{Din}$ faptul că particulele pot să-și modifice masa - după cum s-a demonstrat

\footnotetext{
${ }^{4}$ Ibidem.

${ }^{5}$ Ibidem.
} 
în ultima vreme cu particulele din radiațiile cosmice - sau pur și simplu să-și înceteze existența ca particule, transformânduse în radiație electromagnetică (,anihilarea" electronilor și a pozitronilor), nu se pot trage concluzii asupra dispariției materiei, câmpul electromagnetic trebuind să fie considerat o altă formă a materiei.

Amândouă aceste forme pot trece din una în cealaltă, asemenea substanței lichide care poate lua formă solidă sau gazoasă. Însă astfel de transformări se desfășoară doar cu condiția respectării legilor conservării energiei. Energia nu poate să dispară sau să apară din nimic. Ea poate doar să-și schimbe starea sau forma, rămânând cantitativ aceeași.

Materia se descompune în particulele elementare: neutroni, protoni, mezoni, electroni, pozitroni, etc. Prin mișcarea și interacțiunea acestor particule, are loc generarea câmpului magnetic, a oscilațiilor magnetice și electrice de amplitudine variată, a radiației infraroșii, a luminii albe, a radiației ultraviolete și a radiației gama.

În teologia ortodoxă academică contemporană, Nikolaos Matsoukas subliniază responsabilitatea teologiei de a îmbina elementele teologice revelate cu explicațiile științifice privind acest mod de funcționare al universului descris de paradigmele științifice. Astfel, teologia ortodoxă contemporană trebuie să urmeze metodologia și modelul patristic tradițional, fără să considere greșite explicațiile funcționale ale universului oferite de paradigmele științifice diferite de cele din epoca patristică. În ceea ce privește tema cum a avut loc actul creației, Sfântul Vasile cel Mare și Sfântul Grigorie al Nyssei prezintă opinii remarcabile, care după analogie prezintă asemănări cu pozițiile contemporane ale evoluționiștilor. În cunoscutele faze ale creației, diferitele specii nu au fost create de la început cu forma lor de astăzi, ci 
au provenit din depunerile seminale pe care lucrarea creatoare a lui Dumnezeu le-a depus în pământ. „Sfântul Vasile cel Mare introduce teoriile științifice ale epocii lui și le altoiește funcțional cu relatările Genezei. Consecvent liniei sale că acel cum al creației se lărgește prin cercetare și nu aparține cunoașterii harismatice a inspirației, completează într-un mod foarte interesant informațiile pe care le ia din Sfânta Scriptură. Această îmbinare are datoria să fie făcută de către orice teologie contemporană și să nu se grăbească să condamne teoriile oamenilor de știință." 6

Sfântul Grigorie de Nyssa, completându-1 întru-un anume fel pe Sfântul Vasile cel Mare, vorbește despre creație ca despre o energie (lucrare) instantanee a lui Dumnezeu, prin intermediul căreia sunt create de la început toate depunerile ființelor. După aceea, începe dezvoltarea dinamică și manifestarea tuturor varietăților și mărimilor universului, ale lumii și ale vieții. „In acest mod este construit și omul. Depunerea lui se afla în întregul celorlalte depuneri. Prin urmare, existența lui primordiala nu este nici una istorica, a lui Adam si a Evei, ci una negenerată și seminală. Exact în această depunere seminală există intrinsec, prin preștiința și puterea dumnezeiasca, acel după chipul și după asemănarea, precum și posibilitatea constituirii omului în bărbat şi femeie. [...]Astfel, într-un mod extraordinar de clarificator, în acord cu ethosul teologiei ortodoxe, se poate vedea distincția intre cauza creației și modul realizării și dezvoltării ei." După cuvântătorii de Dumnezeu Părinți, Dumnezeul Treimic se revelează prin cunoașterea harismatică realizată prin intermediul teofaniilor, arătând faptul ca El însuși este cauza și că urmează o modalitate care se află in concordanță cu atotputernicia și atotînţelepciunea Sa. Totuși „,cunoașterea harismatică nu descrie aceasta modalitate

\footnotetext{
${ }^{6}$ Nikolaos Matsoukas, op. cit., pp. 127-128.

${ }^{7}$ Ibidem.
} 
prin mijloace științifice, ci simbolic, chiar și în cadrul unei anumite nuanțe științifice. De aceea, toți Îl accepta pe Dumnezeu drept cauza unică a creației (care s-a făcut din neființa iar nu din substanța Ființei), dar explică modul acestei creații prin concursul cunoașterii științifice"».

De asemenea, Sfântul Luca al Crimeii prezintă succint și arborele filogenetic. „De la clasa protozoarelor se ramifică două lumi grandioase de ființe vii: ale plantelor și ale animalelor. Complexitatea lumii vegetale a ajuns până la forme uimitoare, ca florile minunat mirositoare, palmierii și chiparoșii eleganți, măreții cedri de Liban, stejarii puternici și arborii sequoia, care trăiesc până la trei mii de ani. [...] Este cu totul neîndoielnic că întreaga lume vegetală și animală e înzestrată cu darul primordial al Duhului Sfânt - duhul vieții"’. Pentru omul duhovnicesc, axat pe viața duhovnicească, care cunoaște că nu omul Adam ci Omul Hristos este „cununa creației” $(\mathrm{Col} 1,16)$, paradigma științifică contemporană ce include și dezvoltarea evolutivă exclusiv a vieții biologice descrisă de genetică, nu subminează nicidecum hristocentrismul creației, dimpotrivă îl potențează, acest lucru reieșind foarte clar din viața, activitatea (atât cea duhovnicească cât și cea medicală) precum și din învățătura Sfântului Luca al Crimeii.

În prezent se remarcă relativ ușor marea năzuința a apologeților mai noi de a găsi armonia dintre știința și religie. Rațiunea acestei intenții a fost simplă: ei au identificat conștient, ba chiar și inconștient, de multe ori cauza și modul genezei ființelor ca fiind un lucru cu care se îndeletnicește Sfântă Scriptura și prin extensie teologia. $\mathrm{Cu}$ alte cuvinte ei credeau că Sfântă Scriptură și teologia răspund clar și categoric la cele doua întrebări: 1. Cine a făcut lumea? 2. Cum a făcut-o? Au considerat că „limbajul

\footnotetext{
${ }^{8}$ Ibidem.

${ }^{9}$ Sfântul Luca al Crimeei, op. cit., p.72.
} 
simbolic al relatărilor Genezei de pildă, despre crearea lumii, ajungea să spună exact cum fost făcută lumea și nu doar cine a făcut-o. Aceasta situație a creat nu doar situații nefirești, ci totodată și multe probleme păgubitoare. In acest fel, in Occident, unde cei mai mulți teologi acceptau chiar și în sec. al XIX-lea inspirația literală și, firește, nu cunoșteau nimic despre teologia simbolică a Părinților din Răsărit, adepții lui Darwin erau fie prigoniți - atât cât au putut persecutorii să facă așa ceva -, fie acuzați ca fiind falsificatori ai adevăratei științe, a celei armonizate cu religia după modul încrâncenaților apologeți! Cu timpul însă nevoia i-a condus pe apologeți să se adapteze cerințelor științifice și să înceteze războiul și apologetica. Deci nevoia a fost cea care i-a obligat, iar nu premisele lor teologice, sa facă în final distincția între cine a făcut lumea (învățătura Bibliei și a teologiei inspirate) și cum s-a făcut lumea (limbajul simbolic al Bibliei și lucrarea cercetării științifice, așa cum deja observase in Hexaimeronul său Sfântul Vasile cel Mare in 370!) " 10

Spre deosebire de teologia apuseană (atât cea romano-catolică cât și cea protestantă), teologia ortodoxa a îndelungatei tradiții nu a căzut în cursa vreunei nevoi de armonizare între știința și religie și a putut să distingă separat cele doua teme care se refereau la cine a creat lumea si la cum a fost aceasta creata. Cele doua planuri independente: al teologiei și al științei, au fost unificate funcțional și nu au fost niciodată înțelese dialectic.

Prin urmare „teologia, la fel ca și sfântul scriitor al Genezei, poate să vorbească despre amândouă, despre cauza şi despre modul genezei ființelor, dar are datoria să cunoască faptul că primul aparține în mod clar domeniului teologic, al cunoașterii harismatice, și al doilea spațiului cercetării, al cunoașterii științifice simple și înalte. O asemenea minunată dezvoltare și o neasemuită

${ }^{10}$ Nikolaos Matsoukas, op.cit., p. 124. 
îmbinare a celor doua domenii realizează Sfântul Vasile cel Mare și Sfầntul Grigorie al Nyssei în lucrările lor despre Hexaimeron.”"11 Totuși ,,în teologie, în ceea ce privește modul creației, domina seria evenimentelor primului capitol al Genezei, iar când este vorba despre descrierea creației și a celor create, precum și de fiecare dată când se vorbește despre Paradis (Eden) și despre păcatul strămoșesc, se folosește în mod exclusiv al doilea capitol.

Având în vedere expunerea de mai sus, putem formula următoarele întrebări pertinente: In contextul paradigmei științifice actuale, care sunt limitele ontologice cosmologice? Ce putem spune despre realitatea obiectelor matematice? Care sunt implicațiile cosmologice științifice ale principiului antropic? Care sunt limitele ontologice ale științei? Din punct de vedere teologic catafatic, cum putem exprima dogmatic pertinent, conform metodologiei patristice, utilizând termenii (științifici și filozofici) specifici paradigmei științifice actuale, cogniția intelectuala umană duhovnicească a „zilei a 8-a”, in Sfânta Biserică, mai ales la Sfânta Liturghie.

Acestea sunt desigur doar câteva întrebări fundamentale care frământă omenirea.

Cosmologia, conform paradigmei științifice contemporane, oferă explicații ce tind spre exhaustivitate, în ceea ce privește modul de funcționare al universului. Totuși știința (așa cum o definim în prezent) nu va putea niciodată oferi o explicație științifică pentru cauza și scopul (ontologic) al acestui mod de funcționare al universului, descris paradigmatic prin diverse teorii științifice.

Din punct de vedere misionar ortodox, este o necesitatea imperioasă ca paradigma științifică contemporană să fie analizată după modelul patristic, având la bază metodologia Sfântului Luca al Crimeii, în care, din punct de vedere cosmologic (inclusiv

${ }^{11}$ Ibidem, pp. 124-125. 
antropologic), să fie inechivoc exprimată cauza și scopul hristocentric al creației, întrucât așa cum am precizat mai sus „Cununa creației” este Omul Hristos și nu omul Adam (Col 1,16).

O paradigma creaționistă ortodoxă contemporană (ce implică cosmologia, filogeneza, antropogeneza ş.a.m.d), în asentimentul metodologiei și modelului patristic, care să confere paradigmei științifice contemporane un sens exclusiv și inechivoc hristrocentric, din punct de vedere al cauzei și al scopului, face din cosmologie o veritabilă interfață în dialogul onest între teologia ortodoxă și știință, în beneficiul ambelor părți și evident în detrimentul extremismului (atât a scientismului cât și a fundamentalismul religios).

Astfel, consider că în acest mod, Biserica răspunde adecvat și pertinent cerințelor misionare în sferele intelectuale contemporane, cu impact puternic în domeniul social și cultural, contribuind decisiv la întâlnirea personală a omului cu Hristos Iisus (conform învățăturii și modelului patristic), în Sfânta Biserică, prin Sfintele Taine, ceea ce implică cogniția duhovnicească specifică (antropologic hristocentrică).

Explicarea științifica a funcționalității existențiale a obiectelor fizice (bazată pe mecanismul cauză-efect), nu poate fi separată de sensul existențial filozofic al acestei realități. Dacă fizica clasică considera ca știința poate oferi explicații funcționale paradigmatice independente de observator, existând astfel o realitate obiectivă; în prezent fizica (teoria relativității, mecanica cuantică) afirmă că nu se poate oferi o explicație științifică paradigmatică exhaustivă a acestui mod de funcționare al universului, independent de metoda de cercetare și de observator (omul, ființa care are cogniția intelectuala cea mai avansată și complexă dintre toate ființele cunoscute din univers). Astfel, sunt puse în discuție, pe de o parte atât obiectivitatea și exhaustivitatea 
potențială a paradigmelor științifice, cât mai ales, pe de altă parte, independentă științei față de filozofie, mai precis posibilitatea științei de a oferi o explicații paradigmatice (ale acestui mod e funcţionare al universului), independent de sensul existenţial (filozofic) ale acestui mod de funcționare. „Convingerea despre granița absoluta pe care ar oferi-o observațiile și concluziile științifice, precum și deplina obiectivitate a metodei științifice, este o caracteristica a romantismului, fiind la fel de învechită ca și ea" 12 .

Filotheos Faros afirmă pertinent: „putem spune că știința apuseană a cucerit o mare parte din ceea ce reprezintă cunoașterea umană, adoptând o înțelegere mecanicistă ce s-a extins în acele domenii ale cunoașterii în care justețea aplicării ei era cel puțin suspectă, cum ar fi cercetarea organismelor vii și mai ales a omului”' întrucât existența organismelor vii și mai ales omul, nu pot fi reduse la o explicație fiziologică reducționistă (ce ignoră componenta duhovnicească). Mario Begzos afirmă: ,în vremea noastră distanța dintre teorie și concepția despre lume, dintre știința și scientism, dintre ideologie și epistemologie a ajuns să fie conștientizată într-o mai mare măsura ca altă dată. In același timp, se poate vorbi de o respingere a aşa-zisului caracter formal al cercetării, demitizând-se presupusul caracter neutru al științei fata de politică, artă sau credință, pentru ca în final știința însăși să ajungă să fie dezideologizata" ${ }^{14}$.

\footnotetext{
${ }^{12}$ Pr. Filothei Faros, Mitul bolii psihice, trad. Ovidiu Lăzărescu, Galați, Edit. Egumenita, 2009, p 7.

${ }^{13}$ Ibidem, p 9.

${ }^{14}$ Ibidem, p 9.
} 


\section{Bibliografie}

1. Alexander, Denis, Creatie sau Evolutie. Trebuie sa alegem? București, Edit. Curtea Veche, 2010.

2. Atkins, Peter, Amprenta lui Galileo. Cele 10 mari idei ale științei. Bucureşti, Edit. All, 2007.

3. Ayala, Francisco J, Darul lui Darwin către Știință si Religie. București, Edit. Curtea Veche, 2008.

4. Centrul Bisericesc Munchen, „Teoria evoluției şi creştinismul. Sunt ele incompatibile?" Last modified January 1, 2012, http://cbrom. de/ro/spiritualitate/articole/calin-emilian-cira/teoria-evolutiei-sicrestinismul-sunt-ele-incompatibile.

5. Collins, Francis S, Limbajul lui Dumnezeu, București, Edit. Curtea Veche, 2009.

6. Faros, Filotheos, Mitul bolii psihice. Galați, Edit. Egumenita, 2009.

7. Flonta, Mircea, Darwin şi dupa Darwin. Studii de filozofie a biologiei. București, Edit. Humanitas, 2010.

8. Hart-Davis, Adam, The Book of Time: The Secrets of Time, How It Works and How We Measure It. London, Edit. Mitchell Beazley, 2011.

9. Ică, Ioan, Alexandros Kalomiros, Sfinţii Părinţi despre originile şi destinul cosmosului şi al omului. Sibiu, Edit. Deisis, 2003.

10. Lecourt, Dominique, Dicționar de istoria și filozofia științelor. București, Edit. Polirom, 2009.

11. St. Luca al Crimeii, Puterea inimii. București, Sophia, 2010.

12. Matsoukas, Nikolaos, Introducere în gnoseologia teologică. București, Edit. Bizantină, 1997.

13. Meyendorff, John, O introducere in studiul vieţii şi operei Sfântului Grigorie Palama, Bucuresti, Edit. Nemira, 2014.

14. Moore, Lazarus, Sfântul Serafim de Sarov. O bografie spirituală, Bucureşti, Edit. Agapis, 2002.

15. Pease, Alan, De ce bărbații se uită la meci și femeile se uită în oglindă? De ce suntem diferiți și ce-ar fi de făcut?, București, Edit. Curtea Veche, 2009.

16. Penrose, Roger, Mintea noastră cea de toate zilele. București, Edit. Tehnică, 2006.

17. Robinson, Andrew, Măsura lucrurilor. București, Edit. Art, 2008.

18. Rosemblum, Bruce, Fred Kutter, Enigma Cuantică. București: Prestige, 2011. 


\section{Web Sources}

1. CERN, "Extra Dimensions, Gravitons, and Tiny Black Holes," accessed on February 23, 2011, http://home.web.cern.ch/about/ physics/extra-dimensions-gravitons-and-tiny-black-holes

2. CERN, "The Higgs Boson," accessed on February 23, 2014, http:// home.web.cern.ch/topics/higgs-boson

3. NASA Gravity Probe B, The Relativity Mission, "NASA's Gravity Probe B Confirms Two Einstein Space-Time Theories," accessed February 13, 2011, http://www.nasa.gov/mission_pages/gpb/

4. NASA Wilkinson Microwave Anisotropy Probe, "Cosmology: The Study of the Universe," last modified March 16, 2010, http://map. gsfc.nasa.gov/universe/WMAP_Universe.pdf 
